\title{
Application of Human Error Identification (HEI) Techniques to Cognitive Rehabilitation in Stroke Patients with Limb Apraxia
}

\author{
Charmayne M.L. Hughes ${ }^{1}$, Chris Baber ${ }^{2}$, Marta Bienkiewicz ${ }^{1}$, \\ and Joachim Hermsdörfer ${ }^{1}$ \\ ${ }^{1}$ Institute of Movement Science, Department of Sport and Health Science, \\ Technical University of Munich, 80992 Munich, Germany \\ \{charmayne.hughes, marta.bienkiewicz, joachim. hermsdoerfer\}@tum. de \\ ${ }^{2}$ Electrical, Electronic and Computing Engineering, \\ The University of Birmingham, Birmingham, B15 2TT, U.K. \\ C.BABER@bham.ac.uk
}

\begin{abstract}
The aim of this study was to consider the potential uses of human error identification (HEI) techniques in the development of a Personal Healthcare System (PHS) capable of delivering cognitive rehabilitation of activities of daily living (ADL) for stroke patients with limb apraxia (i.e., CogWatch). HEI techniques were able to predict a number of apraxic errors, as well as the associated consequences. The results of the present study indicate that HEI analysis is a useful tool in the design of cognitive systems that seek to reduce or eliminate errors in apraxic populations. The results will be implemented in the CogWatch system and will be used to develop error reduction strategies that prevent errors from occurring, and to provide post-error feedback to help the user correct their actions.
\end{abstract}

Keywords: Human error identification, apraxia, activities of daily living.

\section{Introduction}

After a stroke incident as many as $24 \%$ of patients suffer from persistent impairments of limb apraxia [1], a cognitive-motor deficit characterized by impairment in the performance of skilled movement, which is operationally defined as a neurological disorder of learned purposive movement skill that is not explained by deficits of elementary motor or sensory systems [2]. Apraxia is frequently caused by relatively large lesions in the territory of the left middle cerebral artery (MCA), resulting in plegia of the contralateral right hand. In the case of right hand plegia, the patient has the use of only the ipsilateral left hand. Further, apraxia does not only affect the side of the body opposite to the cerebral lesion (contralateral limb), but also the ipsilateral side.

In general, research has demonstrated that patients with apraxia have difficulty performing many activities of daily living, often committing errors during action 
planning and execution [3-5]. For example, patients will often omit an action (e.g., turn on the coffee maker without having inserted water) or use an inappropriate object (using a knife to stir the tea) during the performance of ADL [6-7]. Several case studies have shown that some error types are more frequent than others [8-12]. For example, patients with left [6] and right hemisphere stroke [11] generally omit more steps and make more sequence errors during ADL performance. By comparison, addition errors, perseveration errors, quality or spatial errors, and semantic errors are less frequently observed than the more prominent errors.

\subsection{Applying Human Error Identification (HEI) to Cognitive Rehabilitation Systems}

Approaches to Human Error Identification (HEI) range from the generic taxonomies to task-specific failure mode approaches to probabilistic/fault-tree approaches. In Human Factors, perhaps the best known generic taxonomy is Reason's [13] Generic Error Modeling System (GEMS) which considers human error in terms of varieties of slips, lapses and mistakes. GEMS is based on a combination of diary study and accident review and provides a convenient means of classifying error at a high level. A potential problem with applying high-level descriptors of error is that this does not readily lend itself to the design of specific tasks or products; working at a generic level means that one is often left with guidance which is generic and not specific to the design under consideration. Consequently, task-based approaches consider the manner in which specific tasks could 'fail'. In his review of Human Error Identification techniques, Kirwan [14] identified two approaches which follow the broad approach of Failure Mode analysis, i.e., identify the ways in which a given product (or task) is likely to fail, which satisfy the criteria he laid out for a good HEI technique. These approaches were SHERPA (Systematic Human Error Reduction and Prediction Approach) [15], and PHECA (Predictive Human Error Cause Analysis) [16]. Finally, probabilistic approaches, such as HEART [17] seek to define the likelihood of an error occurring given combinations of Performance Shaping Factors.

The purpose of the present study was to ascertain the potential uses of human error identification (HEI) techniques in the development of a Personal Healthcare System (PHS) capable of delivering personalized cognitive rehabilitation of ADL for stroke patients (i.e., CogWatch). For the purposes of this paper, we apply a form of SHERPA to the tasks derived from a Hierarchical Task Analysis. The assumption behind SHERPA (and related forms of failure mode analysis of human error) is that each task a person performs can either result in the desired outcome or can fail in some categorizable manner. Thus, for example, if the goal is to 'pick up a cup' then SHERPA codes the potential failure modes in terms of actions which could be performed on the wrong object (so the person picks up a different object) or wrong actions on the right object (so the person performs another action with the cup, such as push it over) or the actions are not completed (so the person grasps the cup but does 
not lift it). It is important to note that SHERPA's categorization is agnostic as to the causes of these failures; it is only concerned with categorizing likely ways in which a particular goal is not achieved. In terms of reliability and sensitivity of techniques like SHERPA, Baber and Stanton [18] found an inter-rater reliability of 90\%, a validity of 0.8 (with the observation that failure mode approaches tend to have a high 'false alarm' rate, i.e., to over-predict errors which might not be observed).

\section{Procedure}

\subsection{Participants}

Sixteen patients with limb apraxia resulting from lesions following a single cerebrovascular accident (CVA) who also showed clear signs of apraxia in clinical tests (mean age $=55.13 \mathrm{y}, \mathrm{SD}=12.65,3$ left-handed, 13 right-handed, 8 men, 8 women) were examined. Seven patients suffered a right hemisphere lesion which resulted in right hand hemiparesis and were able to perform the task with only the left hand. The remaining nine patients were able to use both hands to perform the task. Sixteen neurologically healthy individuals (mean age $=46.13 \mathrm{y}, \mathrm{SD}=14.34,3$ left-handed, 13 right-handed, 8 men, 8 women) served as control participants.

\subsection{Apparatus and Procedure}

Participants sat at a table with a dimension of $100 \mathrm{~cm} \times 60 \mathrm{~cm}$. There were a total of 14 objects located on the work surface. Each participant was asked to perform a 2 cup tea-making task, in which one cup of tea required milk and two sweetener tablets, and the other cup of tea required a slice of lemon and one sugar cube. Subjects were informed that all the things required to make the tea are on the table, and that they were to inform the experimenter if they required help stabilizing an object. Two trials were performed. Actions were recorded by a video camera (Panasonic HDC-SD909) located $45^{\circ}$ to the right side of the table.

\subsection{Hierarchical Task Analysis}

The first step in a HEI analysis is to obtain an appropriate HTA for the task. The HTA was drawn up by the lead author, and reviewed by the second author as well as two researchers from the Technical University of Munich. The root of the tree is referred to as the task end-goal. In this study the task end-goal was to make two cups of tea (cup1 required milk and 2 sweetener tablets, cup2 required a slice of lemon and 1 sugar cube). The actions required to complete this task (i.e., sub-goals) are shown in the second level of the hierarchy. 


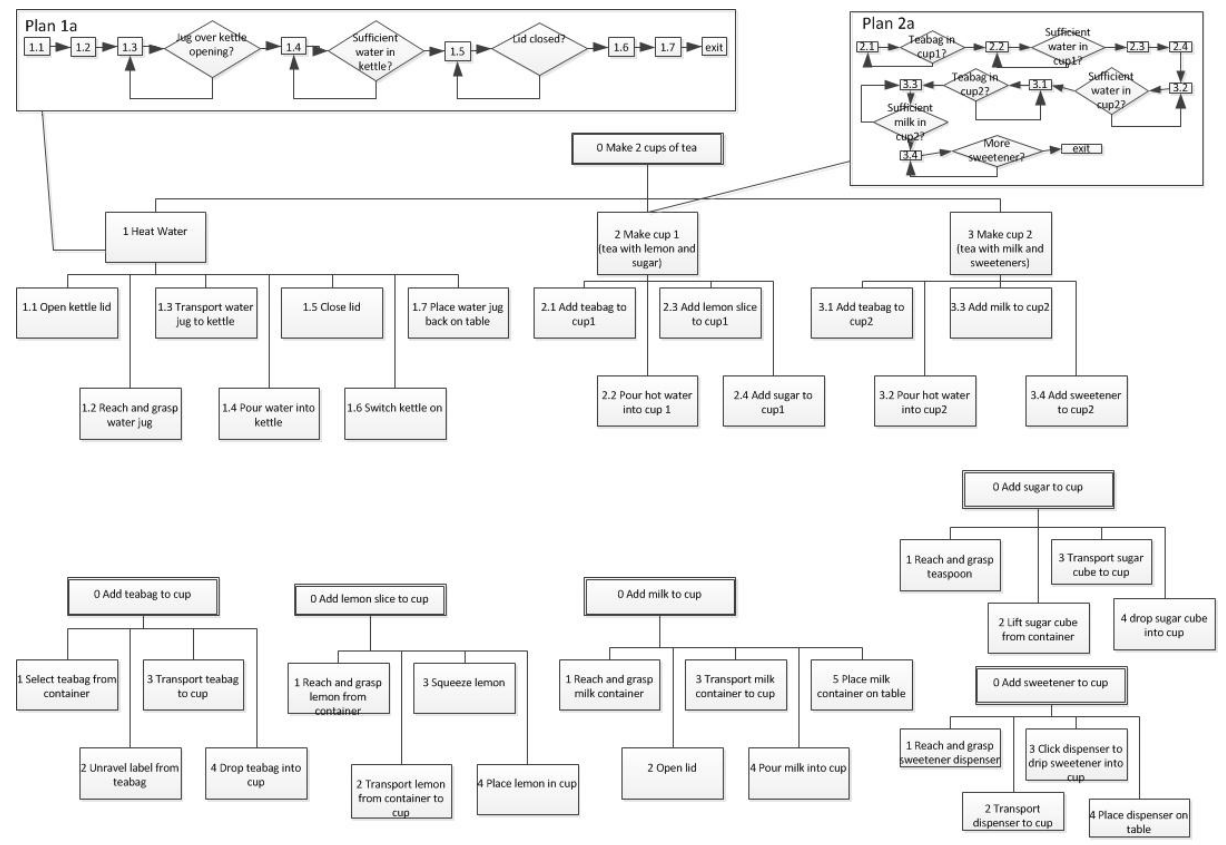

Fig. 1. Hierarchical task analysis (HTA) for the 2 cup tea-making task

\subsection{Human Error Analysis}

In order to conduct the error analysis it was necessary to develop an error production table for the two tea-making task. The table contained information regarding the subgoal in which the error was made. The error analysis was not influenced by task interleaving, thus the HTA described in the previous section could be divided into three sub- goal levels (heat water, make cup1, make cup 2). We also classified errors based on severity. Level 1 refers to errors that are recoverable, such as not pouring enough hot water into cup1. Level 2 refers to errors that prevent the participant from successfully completing the task (e.g., adding coffee to cup1). Level 3 refers to recoverable errors that result in potential harm to the participant (e.g., switching the kettle on before pouring water into the kettle). Lastly, Level 4 errors are those that prevent the participant from successfully completing the task and also result in potential harm to the participant (e.g., dropping the kettle when moving it to position over cup1).

The error analysis prediction table (Table 1) was designed by the lead author, and reviewed by another researcher with apraxia error experience. Inter-rater reliability was calculated separately for potential errors, error severity, and sub-goal. The mean percent agreement was 93\% (range 90-97\%).

There were a total of 54 identified possible errors that could be executed. Potential errors were categorized based on sub-goal and severity (Figure 2A and 2B, black bars). It was predicted that $24 \%$ of errors would occur in the heat water sub-task, $38 \%$ in the make cup1 sub-task, and $44 \%$ in the make cup2 sub-task. When errors were 
categorized by error severity, it was predicted that $16 \%$ would be level 1 errors, $68 \%$ would be level 2 errors, $10 \%$ would be level 3 errors, and 14\% would be level 4 errors. The table also contained a description of each error and error classification. Because it was not feasible to use standard HEI error classification systems to classify errors in the tea making task, errors of action were classified in 12 categories based on previous apraxia literature [7].

Table 1. Summary of action errors typically committed by apraxia patients, and the predicted and observed errors

\begin{tabular}{|c|c|c|}
\hline Error Type & Definitions & Example \\
\hline $\begin{array}{l}\text { Sequence } \\
\text { addition }\end{array}$ & $\begin{array}{l}\text { Adding an extra component action that is } \\
\text { not required in the action sequence }\end{array}$ & Adding instant coffee to cup2 \\
\hline $\begin{array}{l}\text { Sequence } \\
\text { anticipation }\end{array}$ & Performing a subtask earlier than usual & $\begin{array}{l}\text { Turning the kettle on before pouring water } \\
\text { into the kettle }\end{array}$ \\
\hline $\begin{array}{l}\text { Sequence } \\
\text { omission }\end{array}$ & $\begin{array}{l}\text { An action sequence in which one subtask } \\
\text { is not performed }\end{array}$ & $\begin{array}{l}\text { Turning on the kettle on without having } \\
\text { inserted water }\end{array}$ \\
\hline Sequence & $\begin{array}{l}\text { Performing a subtask much later than } \\
\text { usual }\end{array}$ & $\begin{array}{l}\text { Switch kettle on after preparing both cups } \\
\text { of tea }\end{array}$ \\
\hline $\begin{array}{l}\text { Ingredient } \\
\text { omission }\end{array}$ & $\begin{array}{l}\text { Failing to add an ingredient required to } \\
\text { complete the task goal }\end{array}$ & Failing to put sugar into cup1 \\
\hline $\begin{array}{l}\text { Ingredient } \\
\text { substitution }\end{array}$ & $\begin{array}{l}\text { An intended action carried out with an } \\
\text { unintended ingredient }\end{array}$ & $\begin{array}{l}\text { Pouring coffee grounds instead of sugar } \\
\text { into cup } 2\end{array}$ \\
\hline $\begin{array}{l}\text { Object } \\
\text { substitution }\end{array}$ & $\begin{array}{l}\text { An intended action carried out with an } \\
\text { unintended object }\end{array}$ & Pour heated water into non-cup object \\
\hline Execution & An error in the execution of the task & Dropping a cup onto the table \\
\hline Misestimation & $\begin{array}{l}\text { Using grossly too much or too little of } \\
\text { some substance }\end{array}$ & $\begin{array}{l}\text { Pouring half of the milk jug contents into } \\
\text { cup2 }\end{array}$ \\
\hline Mislocation & $\begin{array}{l}\text { An action that is appropriate to the ob- } \\
\text { ject, but is performed in the wrong place }\end{array}$ & $\begin{array}{l}\text { Pouring some liquid from the bottle onto } \\
\text { the table rather than into the glass }\end{array}$ \\
\hline Quality & $\begin{array}{l}\text { The action was carried out, but in an } \\
\text { inappropriate way }\end{array}$ & $\begin{array}{l}\text { Putting the tea bag and the paper label into } \\
\text { a cup }\end{array}$ \\
\hline Perseveration & $\begin{array}{l}\text { The unintentional repetition of a step or } \\
\text { subtask }\end{array}$ & Adding more than one sugar cup to cup2 \\
\hline
\end{tabular}

\subsection{Consequence Analysis}

Based on the possible errors developed in the previous section, it was possible to predict the consequences for each of the identified errors. For example, if the participant switched the kettle on without adding water (error) this would burn out the element in the kettle (consequence). The list of potential consequences was developed by the first author, and reviewed by a trained assistant. The level of rater agreement was $97 \%$. 


\section{$3 \quad$ Results}

\subsection{Activity Sampling}

To ascertain how apraxic patients and healthy controls perform the 2 cup tea-making task two individuals (lead author and a trained assistant) scored the recorded videos separately with respect to the sub-goals in Figure 1. Inter-rater agreement was $95.4 \%$. Activity sampling provides an opportunity to describe alternative ways in which subgoals can be sequenced. For ease of reading, specific information regarding plans have been omitted from the HTA diagram. That said, in general it was observed that control participants performed the sub-goal "heat water" using varying plans, whereas the apraxia patients always used the same plan. For the sub-goal "make tea" there was no clear preference for an action sequence plan for either control participants and for apraxia patients. Furthermore, there was a distinct difference in "make tea" plans between the groups, such that control participants preferred one set of action plans, whereas the apraxia patients preferred another set. Lastly, and perhaps most interestingly, both control and apraxic individuals used a different action plan for the first and second trial for the sub-goal "make tea."

\subsection{Human Error Analysis}

Analysis indicated that control participants successfully completed the task in $88 \%$ of trials. There were four errors committed, which was comprised of two ingredient substitution (adding sugar cubes instead of sweetener to cup2), and two ingredient omission errors (failing to add milk to cup2). In contrast, apraxia patients committed errors in $57.1 \%$ of trials, with a total of 50 errors recorded. The number of errors per trials ranged from $0-7$ (mean $=2.84, \mathrm{SD}=2.0)$. Table 2 presents a summary of the HEI error analysis, restricted to errors which were observed on more than two occasions (due to the large number of possible errors that were committed).

The most frequently occurring error was that of ingredient omission $(30 \%$ of errors), with patients typically failing to put tea bags into one or both cups, or adding one or both sweetener tablets to cup2. There were also a number of trials in which apraxia patients placed too much of too little of an ingredient into either cup (misestimation $=20 \%$ ), omitted a step in the action sequence (sequence omission $=16 \%$ ), or substituted an unnecessary ingredient for a necessary one (ingredient substitution = $16 \%)$. There was a small number for sequence addition (6\%), quality (4\%), execution $(4 \%)$, sequence anticipation $(2 \%)$ and sequence $(2 \%)$ errors. Lastly, we did not observe any mislocation or perseveration errors.

Errors were also categorized based on sub-goal and severity. Analysis indicated that the number of errors produced by apraxia patients was higher for the "make cup2" (42\%) and the "make cup1" (34\%) sub-tasks, compared to the "heat water" sub-task (24\%). When errors were classified by error severity, it was evident that the vast majority of errors $(82 \%)$ resulted in a fatal error that prevented the successful completion of the task (level 2). There were also a small number of trials involving 
level 1 (recoverable error: 10\%) and level 4 (fatal error that also resulted in potential harm to the user: $8 \%$ ). There were no recoverable errors that resulted in potential harm to the participant (level 3).

Table 2. Outcome of human error analysis

\begin{tabular}{|c|c|c|c|c|c|}
\hline $\begin{array}{l}\text { Task } \\
\text { Step }\end{array}$ & $\begin{array}{l}\text { Error } \\
\text { Category }\end{array}$ & Description & Consequence & $\begin{array}{c}\text { Error } \\
\text { Severity }\end{array}$ & $\begin{array}{c}\# \\
\text { trials }\end{array}$ \\
\hline \multirow[t]{2}{*}{1} & SO & $\begin{array}{l}\text { Fail to put water into } \\
\text { kettle }\end{array}$ & Unable to heat water & 4 & 3 \\
\hline & Q & $\begin{array}{l}\text { Not waiting for water to } \\
\text { boil }\end{array}$ & $\begin{array}{l}\text { Water will not be hot enough } \\
\text { to infuse tea ingredients }\end{array}$ & 2 & 2 \\
\hline 1.4 & ME & $\begin{array}{l}\text { Not pouring enough } \\
\text { water into kettle }\end{array}$ & $\begin{array}{l}\text { Unable to make } 2 \text { full cups of } \\
\text { tea }\end{array}$ & 1 & 3 \\
\hline \multirow[t]{2}{*}{2.1} & IO & $\begin{array}{l}\text { Fail to add teabag into } \\
\text { cup1 }\end{array}$ & Required ingredient not added & 2 & 3 \\
\hline & IS & $\begin{array}{l}\text { Add coffee instead of tea } \\
\text { bag into cup } 1\end{array}$ & $\begin{array}{l}\text { Required ingredient not added, } \\
\text { Incorrect ingredient added, tea } \\
\text { will have incorrect taste }\end{array}$ & 2 & 4 \\
\hline 2.2 & SO & $\begin{array}{l}\text { Did not pour water into } \\
\text { cup } 1\end{array}$ & $\begin{array}{l}\text { Incorrect ingredient added, } \\
\text { unable to make a cup of tea }\end{array}$ & 2 & 2 \\
\hline 2.3 & ME & $\begin{array}{l}\text { Add more than one sugar } \\
\text { cube }\end{array}$ & $\begin{array}{l}\text { Incorrect ingredient added, } \\
\text { tea will have incorrect taste }\end{array}$ & 2 & 2 \\
\hline 2.4 & IO & Fail to add lemon to cup1 & Required ingredient not added & 2 & 4 \\
\hline \multirow[t]{2}{*}{3.1} & IO & $\begin{array}{l}\text { Fail to add teabag into } \\
\text { cup2 }\end{array}$ & Required ingredient not added & 2 & 3 \\
\hline & IS & $\begin{array}{l}\text { Add coffee instead of tea } \\
\text { bag }\end{array}$ & $\begin{array}{l}\text { Required ingredient not added, } \\
\text { Incorrect ingredient added, } \\
\text { tea will have incorrect taste }\end{array}$ & 2 & 2 \\
\hline 3.2 & ME & $\begin{array}{l}\text { Not pouring enough } \\
\text { water into cup2 }\end{array}$ & $\begin{array}{l}\text { A full cup of tea will not be } \\
\text { made }\end{array}$ & 2 & 2 \\
\hline 3.3 & IO & Fail to add milk to cup2 & Required ingredient not added & 2 & 2 \\
\hline \multirow[t]{3}{*}{3.4} & IO & $\begin{array}{l}\text { Fail to add sweetener to } \\
\text { cup2 }\end{array}$ & Required ingredient not added & 2 & 3 \\
\hline & IS & $\begin{array}{l}\text { Add sugar instead of } \\
\text { sweetener }\end{array}$ & $\begin{array}{l}\text { Incorrect ingredient added, } \\
\text { Required ingredient not added, }\end{array}$ & 2 & 2 \\
\hline & EX & $\begin{array}{l}\text { Drop sweetener tablet } \\
\text { outside of cup2 }\end{array}$ & $\begin{array}{l}\text { Required ingredient not added, } \\
\text { possible ingredient contamina- } \\
\text { tion }\end{array}$ & 1 & 2 \\
\hline
\end{tabular}

The observed errors were then compared to those predicted. That analysis revealed that HEI analysis successfully predicted 24 of the 26 observed errors. In our predictions we classified the act of adding coffee into cup1 or cup2 as an addition error (i.e., adding coffee and a tea bag), but did not consider the possibility that an individual would add coffee instead of a tea bag (ingredient substitution error). We also failed to include the "not waiting for the water to boil before pouring water" error (quality error). However, as is often the case in HEI, there were a number of predicted errors that were not observed (44\%) in these trials. In contrast to our expectations, apraxic 
patients did not commit mislocation (e.g., pouring milk into water jug instead of cup1) or perseveration errors (repeatedly performing the pour water into the kettle sub-task).

\subsection{Consequence Analysis}

The HEI technique was particularly useful when the predicted consequences were compared with what was actually observed. With the exception of one error and its associated consequence (switch kettle on an incorrect time which leads to the burn out of the element), all consequences were observed after their respective error occurred (96.1\% successful prediction).

\subsection{Error Reduction Strategies}

Based on the obtained results it was possible to generate a list of possible error reduction strategies that could implemented in a cognitive rehabilitation system in order to reduce or prevent errors in apraxic populations. These strategies were divided into prospective and feedback. Prospective strategies include verbal and visual spatiotemporal cues (via simulated avatars) that indicate the next most probable action sequence of the task. Feedback strategies include auditory messages generated by the CogWatch virtual task execution (VTE) module, and vibration signals (constant and pulsed) delivered through the CogWatch wrist device. The strength and the content of the feedback warning signal will depend on the error severity of the error committed.

\section{Conclusions}

In summary, the results of the present study indicate that HEI analysis is a useful tool in the design of cognitive systems that seek to reduce or eliminate errors in apraxic populations. HEI techniques were able to predict a number of apraxic errors, as well as the associated consequences. The apraxia results are to be implemented in the CogWatch system and will be used to develop error reduction strategies that prevent errors from occurring, and to provide post-error feedback to help the user correct their actions. The observed probabilities associated with action sequencing and error analysis will be integrated into the $\mathrm{CogWatch}$ action recognition task models.

Acknowledgments. The authors wish to thank Georg Goldenberg for access to patients, Saskia Steinl and Rhoia Neidenbach for help with data collection, Alexander Matschl for data analysis, and CogWatch cooperation partners for their insightful comments. This study was supported by a grant from the European Commission (FP7-ICT-2011-288912). 


\section{References}

1. Bickerton, W., Riddoch, M.J., Samson, D., Balani, A., Mistry, B., Humphreys, G.W.: Systematic assessment of apraxia and functional predictions from the Birmingham Cognitive Screen. Journal of Neurology, Neurosurgery, and Psychiatry 83, 513-521 (2012)

2. Rothi, L.J.G., Heilman, K.M.: Apraxia: The Neuropsychology of Action. Psychology Press, East Sussex (1997)

3. Buxbaum, L.J., Schwartz, M.F., Montgomery, M.W.: Ideational apraxia and naturalistic action. Cognitive Neuropsychology 15, 617-643 (1998)

4. De Renzi, E.: Apraxia. In: Boller, F., Grafman, J. (eds.) Handbook of Neuropsychology, Amsterdam, pp. 245-263. Elsevier, New York (1989)

5. Buxbaum, L.J., Schwartz, M.F., Montgomery, M.W.: Ideational apraxia and naturalistic action. Cognitive Neuropsychology 15, 617-643 (1998)

6. Schwartz, M.F., Montgomery, M.W., Buxbaum, L.J., Lee, S.S., Carew, T.G., Coslett, H.B., Ferraro, M., Fitzpatrick-DeSalme, E., Hart, T., Mayer, N.: Naturalistic action impairment in closed head injury. Neuropsychology 12, 13-28 (1998)

7. Schwartz, M.F., Reed, E.S., Montgomery, M., Palmer, C., Mayer, N.H.: The Quantitative Description of Action Disorganization After Brain-Damage - A Case-Study. Cognitive Neuropsychology 8, 381-414 (1991)

8. Humphreys, G.W., Forde, E.M.E.: Disordered action schema and action disorganisation syndrome. Cognitive Neuropsychology 15, 771-811 (1998)

9. Morady, K., Humphreys, G.: Multiple task demands in action disorganization syndrome. Neurocase 17, 461-472 (2011)

10. Schwartz, M.F.: Re-examining the role of executive functions in routine action production. Structure and Functions of the Human Prefrontal Cortex 769, 321-335 (1995)

11. Schwartz, M.F., Buxbaum, L.J., Montgomery, M.W., Fitzpatrick-DeSalme, E., Hart, T., Ferraro, M., Lee, S.S., Coslett, H.B.: Naturalistic action production following right hemisphere stroke. Neuropsychologia 37, 51-66 (1999)

12. Schwartz, M.F., Montgomery, M.W., Fitzpatrick-desalme, E.J., Ochipa, C., Coslett, H.B., Mayer, N.H.: Analysis of a disorder of everyday action. Cognitive Neuropsychology 12, 863-892 (1995)

13. Reason, J.T.: Human Error. Cambridge University Press, New York (1990)

14. Kirwan, B.: Human error identification in human reliability assessment. Part 1: overview of approaches. Applied Ergonomics 23, 299-318 (1992)

15. Embrey, D.: SHERPA: a systematic human error reduction and prediction approach. In: Proceedings of the International Topical Meeting on Advances in Human Factors in Nuclear Power Systems, Knoxville, Tennessee (1986)

16. Whalley, S.P.: Minimising the cause of human error. In: Proceedings of the 10th Advances in Reliability Symposium. Elsevier, Amsterdam (1988)

17. Williams, J.C.: HEART: a proposed method for assessing and reducing human error, Birmingham. Presented at 9th Advances in Reliability Technology Symposium, Birmingham (1986)

18. Baber, C., Stanton, N.A.: Human error identification techniques applied to public technology: predictions compared with observed use. Applied Ergonomics 27, 119-131 (1996) 